\title{
EFFECT OF SINTERING TIME ON THE MICROSTRUCTURE AND MECHANICAL PROPERTIES OF (Ti,Ta)(C,N)-BASED CERMETS.
}

\author{
E. Chicardi*1, Y. Torres ${ }^{2}$, J. M. Córdoba ${ }^{1}$, M. J. Sayagués ${ }^{1}$, J. A. Rodríguez ${ }^{2}$ and F. J. \\ Gotor $^{1}$ \\ ${ }^{1}$ Instituto de Ciencia de Materiales de Sevilla (US-CSIC), Av. Américo Vespucio 49, \\ 41092 Sevilla, Spain.
}

${ }^{2}$ Dpto. de Ingeniería Mecánica y de los Materiales, E.T.S. de Ingeniería, Universidad de Sevilla, Avda. Camino de los Descubrimientos s/n, 41092 Sevilla, Spain.

\begin{abstract}
Complete solid-solution cermets based on titanium-tantalum carbonitride using a starting nominal composition with 80 wt. $\%$ of $\left(\mathrm{Ti}_{0.8} \mathrm{Ta}_{0.2}\right)\left(\mathrm{C}_{0.5} \mathrm{~N}_{0.5}\right)$ and 20 wt. $\%$ of Co were performed by pressure-less sintering at $1550{ }^{\circ} \mathrm{C}$ for different times (from 0 to 180 min) in an inert atmosphere. Chemical and phase analyses were conducted using X-ray diffraction (XRD), elemental analysis and energy dispersive X-ray spectrometry (EDX). The binder mean free path and the contiguity of the carbonitride particles were used to rationalise the microstructural effects of the mechanical behaviour. Mechanical characterisation included determining the Vickers hardness, the fracture toughness (conventional indentation microfractures, IM), the dynamic Young's modulus (ultrasonic technique), the biaxial strength (ball on three ball) and a detailed fractographic examination. Finally, the experimental findings were combined with a theoretical fracture mechanics analysis to estimate the critical processing flaw sizes. Binder-less carbonitride clusters, pores and coarse carbonitride grains were the main defects observed and were responsible for the fractures.
\end{abstract}

\footnotetext{
Keywords: complete solid-solution cermet; titanium carbonitride; mechanosynthesis; microstructure; mechanical behaviour.

*Corresponding Author. E-mail: ernesto.chicardi@icmse.csic.es Phone: +34 954489217 Fax: +34 954460665
} 


\section{INTRODUCTION.}

Cermets based on titanium carbonitride (TiCN) attract the attention of researchers due to their high hardness at high temperature, thermal conductivity, chemical, thermal and wear resistances and low friction coefficient to metals [1-5]. They have been successfully applied to new developments in the field of cutting tools and improve the surface finishing compared to $\mathrm{WC}-\mathrm{Co}$ hard metals, ensuring excellent chip and tolerance control and the dimensional accuracy of the work pieces $[1-3,5,6]$.

Many studies have been reported on phase composition modifications by the use of cermet additives, such as binary carbides and transition metals in the binder alloy, to modulate the microstructure and, consequently, the mechanical properties [7-10]. Particularly, $\mathrm{TaC}$ and $\mathrm{NbC}$ are added to enhance high-temperature hardness and thermal shock resistance, and $\mathrm{Mo}_{2} \mathrm{C}$ and $\mathrm{WC}$ are added to increase sinterability and fracture strength. The presence of these binary carbides induces a core-rim microstructure in the ceramic grains during liquid phase sintering [11]; this is the result of the formation of complex carbonitride solid solutions containing $\mathrm{Ti}$ and other transition metals, such as $\mathrm{Nb}$, Ta, Mo and/or W, which reprecipitate on the undissolved TiCN particles.

It has been proven that these complex carbonitride solid solutions are responsible for the desirable properties of cermets [12]. For this reason, the use of complete solid-solution cermets (CSCs) [13], i.e., cermets containing ceramic particles without the core-rim microstructure but with the chemical composition of the rim phase, has been proposed to encourage further improvement of the mechanical properties. Using CSCs would avoid the presence of the interface between the core and rim that generates residual stresses and crack propagation [14]. 
To date, few reports have focused on this issue because the manufacture of CSS cermets requires the use of complex transition metal carbonitrides (not a mixture of binary carbides) as the raw ceramic material, and the synthesis of these solid solutions is a difficult task. However, previous work has shown that a mechanochemical process, mechanically induced self-sustaining reaction (MSR), is a suitable method to obtain these complex carbonitrides with stoichiometric control [15]. Recently, the MSR procedure has been successfully applied in the development of CSS cermets [16].

The aim of this work was to carry out an exhaustive characterisation of the mechanical properties of CSC cermets with a starting nominal composition of $80 \mathrm{wt} . \%$ $\left(\mathrm{Ti}_{0.8} \mathrm{Ta}_{0.2}\right)\left(\mathrm{C}_{0.5} \mathrm{~N}_{0.5}\right)$ and 20 wt.\% Co. To the best of our knowledge, this is the first time a study was conducted on the influence of the microstructure on the mechanical behaviour of this type of cermet. The microstructure of the CSC cermets was modified by changing the sintering time of the pressure-less procedure used, and a comprehensive microstructural and mechanical characterisation was performed for each cermet. The following mechanical characteristics were measured: Vickers hardness, fracture toughness (conventional indentation microfracture), dynamic Young's modulus (nondestructive ultrasound technique) and biaxial strength (ball on three balls). Furthermore, the experimental findings were combined with a detailed fractographic examination to estimate the nature and size of the critical processing flaws. 


\section{EXPERIMENTAL.}

\subsection{Processing of samples.}

Titanium powder (99\% in purity, < 325 mesh, Strem Chemicals), tantalum powder (99.6\% in purity, $<325$ mesh, Alfa-Aesar), graphite powder $(<270$ mesh, Fe $\leq$ 0.4\%, Merck), cobalt powder $(99.8 \%$ in purity, $<100$ mesh, Strem Chemicals) and nitrogen $\left(\mathrm{H}_{2} \mathrm{O}\right.$ and $\mathrm{O}_{2} \leq 3 \mathrm{ppm}$, Air Liquide) were used by MSR to synthesise the CSC powdered cermets with a composition of 80 wt.\% $\left(\mathrm{Ti}_{0.8} \mathrm{Ta}_{0.2}\right)\left(\mathrm{C}_{0.5} \mathrm{~N}_{0.5}\right)$ and 20 wt.\% Co. This method takes advantage of the strong exothermic character of carbonitride formation to promote self-propagating reactions during milling. The details of the powder synthesis can be found in a previous work [16].

Powdered cermets were compacted by uniaxial pressing at 2 tons for $5 \mathrm{~min}$ and by subsequent cold isostatic pressing at $200 \mathrm{MPa}$ for $10 \mathrm{~min}$ to yield cylinders of 12 $\mathrm{mm}$ in diameter and $20 \mathrm{~mm}$ in height. The green compacts were sintered at $1550{ }^{\circ} \mathrm{C}$ in a horizontal tubular furnace (Type IGM1360 model no. RTH-180-50-1H, AGNI) under an inert atmosphere (Ar, $\mathrm{H}_{2} \mathrm{O} \leq 8 \mathrm{ppm}$ and $\mathrm{O}_{2} \leq 2 \mathrm{ppm}$, Linde) for different sintering times: $0 \mathrm{~min}, 30 \mathrm{~min}, 60 \mathrm{~min}$, and $180 \mathrm{~min}$. The heating and cooling rates were 10 ${ }^{\circ} \mathrm{C} /$ min between room temperature and $1000{ }^{\circ} \mathrm{C}$ and $5{ }^{\circ} \mathrm{C} / \mathrm{min}$ between $1000{ }^{\circ} \mathrm{C}$ and $1550^{\circ} \mathrm{C}$.

\subsection{Chemical, microstructural, and physical characterisation.}

Cross sections of the sintered cermets were grounded and polished using diamond as the abrasive during several steps. The polished surfaces underwent X-ray diffraction (XRD), which was obtained with a Panalytical X'Pert Pro instrument equipped with a $\theta / \theta$ goniometer using $\mathrm{Cu} \mathrm{K} \alpha$ radiation $(40 \mathrm{kV}, 40 \mathrm{~mA})$, a secondary $\mathrm{K}_{\beta}$ 
filter, and an $X^{\prime}$ Celerator detector. The diffraction patterns were attained by scanning from $20^{\circ}$ to $80^{\circ}(2 \theta)$ in step-scan mode with $0.02^{\circ}$ steps and a counting time of 275 s/step. Silicon powder (Standard Reference Material 640c, NIST) was used for the calibration of the diffraction line positions.

Scanning electron microscopy images were obtained on a Hitachi S-4800 SEMFEG microscope on the polished cermet surfaces. The microstructural parameters were evaluated by image analysis (IA) with the Image-Pro Plus 6.2 software, using 5 pictures of $\mathrm{X} 2 \mathrm{k}$ for each polished cermet. The main parameters estimated by this method were the following: i) the particle size distribution of the carbonitride phase, $\boldsymbol{L}$; ii) the fraction of the binder phase, $\boldsymbol{F}_{\boldsymbol{B}}$; iii) the contiguity of the carbonitride particles, $\boldsymbol{C}$; iv) the binder mean free path, $\lambda$; and iv) the porosity content [17-19].

The transition metal content in the ceramic and binder phases was measured by energy dispersive X-ray spectrometry (EDX) with detectors coupled in the Hitachi microscope. The carbon and nitrogen content in the cermets was determined by elemental analysis made by an LECO elemental analyser (mod.CNHS-932).

Bulk density measurements were carried out using Archimedes' method with distilled water impregnation. This method was chosen for its experimental simplicity and reasonable reliability (ASTM C373-88) [20].

\subsection{Mechanical testing.}

The measurement of the dynamic Young's modulus was performed with a Krautkramer USM $35{ }^{\circledR}$ flaw detector from the longitudinal and transverse propagation velocities of acoustic waves. To evaluate longitudinal waves, a Panametric S-NDT® 4 
MHz ultrasonic transducer was used with an ultrasonic couplant (Sonotrace grade 30®). For transverse waves, a Panametric S-V153® $1.5 \mathrm{MHz}$ shear wave transducer was used with a shear wave couplant (Panametrics-NDT ${ }^{\mathrm{TM}}$ ) [21]. The wave velocities through samples were measured by minimising the delay times of the transducers by following an iterative measurement protocol. The dynamic Young's modulus was calculated from equation 1:

$$
E_{d}=\rho \frac{v_{T}^{2}\left(3 v_{L}^{2}-4 v_{T}^{2}\right)}{v_{L}^{2}-v_{T}^{2}}
$$

where $\rho$ is the density $\left(\mathrm{g} / \mathrm{cm}^{3}\right)$, and $\mathrm{V}_{\mathrm{L}}$ and $\mathrm{V}_{\mathrm{T}}$ are the longitudinal and transverse velocities, respectively.

Hardness was measured at three different loads (1 kgf, $3 \mathrm{kgf}$ and $5 \mathrm{kgf}$ ) using a Vickers diamond pyramidal micro indenter (Zwick 3212) on the polished cermet surfaces. Ten indentations were made for each load. The fracture toughness was evaluated by the indentation microfracture (IM) method using the equations from Shetty et al. [22, 23].

The flexural strength was measured under uniaxial stress using the ball on three balls test (B3B-test) [24-28], where a disc specimen is supported on three balls and loaded symmetrically by a fourth ball. In this loading situation, the three-point support guarantees three well-defined point contacts. At the midpoint of the disc surface opposite of the loading ball, a biaxial tensile stress state exists, which is used for the biaxial strength testing. This test has been recognised to be tolerant for imperfect disc flatness, an imperfection in other small geometries or some misalignment $[24,25]$. Furthermore, the friction is significantly smaller than in the commonly used bending tests. For these reasons, the B3B-test can also be used for the as-sintered and small 
specimens. The biaxial flexural test was carried out at room temperature using an electromechanical universal testing machine. The load application rate was $100 \mathrm{~N} / \mathrm{s}$. The tensile loaded surfaces of the B3B specimens (disks of $1 \mathrm{~mm}$ in thickness and 12 $\mathrm{mm}$ in diameter) were carefully machined, grounded and polished to avoid surface damage. At least three samples were evaluated for each sintering time.

After mechanical testing, selected specimens were taken and subjected to a detailed fractographic examination by scanning electron microscopy, paying special attention to discern the origin, nature, geometry, and size of the strength-limiting flaws, as well as the fracture micromechanisms associated with the different sintering times. Finally, a comparison of the estimated and experimentally determined critical flaw sizes using the IM method and measurements of the defects by fractography was made within the framework of the Linear Elastic Fracture Mechanics (LEFM). 


\section{RESULTS AND DISCUSSIONS.}

\subsection{Chemical and microstructural characterisation.}

The XRD diagrams corresponding to the cermets sintered at $1550{ }^{\circ} \mathrm{C}$ for increasing times are shown in figure 1. For all samples, the ceramic phase is ascribed to a titanium-tantalum carbonitride of the general formula $\mathrm{Ta}_{\mathrm{y}} \mathrm{Ti}_{1-\mathrm{y}} \mathrm{C}_{\mathrm{x}} \mathrm{N}_{1-\mathrm{x}}$, in accordance with the reference diffraction patterns of titanium and tantalum carbides and nitrides. The fact that the ceramic phase reflections remained at the same $2 \theta$ position regardless of the sintering time suggested a constant chemical composition of the carbonitride solid solution. Combining titanium and tantalum quantification by EDX analysis (average of 30 measurements in different ceramic particles) with carbon and nitrogen quantification by elemental analysis (assuming that carbon and nitrogen only come from the ceramic phase), it was possible to estimate the following chemical composition for the ceramic phase: $\mathrm{Ta}_{0.15} \mathrm{Ti}_{0.85} \mathrm{C}_{0.67} \mathrm{~N}_{0.33}$.

Careful examination of the XRD reflections corresponding to the binder and indexing and comparing them to the reference diffraction patterns $\mathrm{Co}_{2} \mathrm{Ti}$ (05-0719), $\mathrm{Co}_{2.2} \mathrm{Ta}_{0.8}$ (15-0031), $\mathrm{Co}_{0.745} \mathrm{Ta}_{0.255}$ (38-07359) and CoTa (42-1212) showed that the binder was composed of intermetallic solid solutions belonging to the Ti-Ta-Co ternary system. The presence of titanium and tantalum in the binder was confirmed by EDX measurements and explains the slight difference between the chemical composition of the ceramic phase and the starting stoichiometry. The existence of the binder in intermetallic phases, which were formed during the sintering process, has been previously reported $[16,29]$. In cermets sintered for 0,30 and $60 \mathrm{~min}$, the presence of two different binder phases was observed: a major phase with a hexagonal structure $\left(\boldsymbol{P 6 _ { 3 }} / \mathbf{m m c}\right)$ and a 1:2 $\left(\mathrm{Ti}_{\mathrm{x}} \mathrm{Ta}_{1-\mathrm{x}} \mathrm{Co}_{2}\right)$ stoichiometry and a minor phase with a 
rhombohedral structure $(\boldsymbol{R}-3 \boldsymbol{m})$ and a 1:1 $\left(\mathrm{Ti}_{\mathrm{x}} \mathrm{Ta}_{1-\mathrm{x}} \mathrm{Co}\right)$ stoichiometry. However, only the hexagonal structure phase was present in the cermet sintered for $180 \mathrm{~min}$.

SEM images were used to characterise the microstructure and evaluate some microstructural parameters in the sintered cermets. The representative micrographs shown in figure 2 confirm that the cermets did not have the characteristic core-rim microstructure. The particle size distribution of the ceramic phase was determined by the image processing software using the linear intercept method [30]. The growth of the ceramic particles was controlled primarily by coalescence phenomena, thus producing larger particles with a wider size distribution with increasing sintering time. Moreover, cermets sintered for 180 min showed a bimodal size distribution as a result of the coalescence and agglomeration of the largest ceramic particles.

$\boldsymbol{C}$ and $\lambda$ were calculated and are shown in table 1. While $\boldsymbol{C}$ decreased with increasing sintering time, $\lambda$ increased; in both cases, this was due to the growth of ceramic particles, which gave rise to larger particles as the sintering time was prolonged.

To assess the quality of the sintering process, the porosity of the cermets was also determined by image processing and is shown in the tables in figure 2 . The expected decrease of porosity with sintering time was observed up to a 60 min sintering time due to increasing densification. However, after 180 min of sintering, the porosity was significantly larger. The microstructure of this cermet, shown in figure $2 \mathrm{~d}$, is characterised by large ceramic agglomerates with trapped pores, which was the consequence of an enhanced ceramic coalescence accompanied by a slight loss of molten binder through gravity that was observed during the long sintering process. The determination of the volume fraction of the binder phase by image processing confirmed a slightly lower binder content in this cermet (see attached tables in figure 2). 


\subsection{Mechanical characterisation.}

The dynamic Young's modulus, measured by a non-destructive ultrasound technique (figure 3a), showed an increase of stiffness with sintering times up to $60 \mathrm{~min}$, in accordance with the decreasing porosity trend with sintering time [31]. The significantly low value of the Young's modulus observed in the cermet sintered for 180 min was due to the increase of porosity previously mentioned. Furthermore, the slight variation in the binder composition observed for this cermet can also affect the value of the Young's modulus. Additionally, the logarithm of the Young's modulus was plotted against the porosity (figure 3b), according to Ryshkevitch equation [32], to obtain a Young's modulus for a fully dense material. This value was approximately $682 \mathrm{GPa}$, which is a higher value than those reported in the literature for cermets $[5,33]$ and hard metals with similar binder contents [34].

The Vickers hardness of cermets measured at 1, 3 and $5 \mathrm{kgf}$ is shown in figure 3c. The effect of the indentation load on the hardness was significant. A general trend of an increasing hardness with a decreasing load, especially at $1 \mathrm{kgf}$, was observed. The assumption that the hardness is independent of the load is only valid in homogeneous and continuous media. Hardening due to the strain gradient plasticity in two-phase materials with a different hardness (the binder and the ceramic are not polished with same velocity) is observed when the length scales of the imposed deformation gradients are comparable to the microstructure length scale of the material [35-37]. On the microscale, the microstructure of the material can be considered an inhomogeneity, and only when the volume affected by the indentation is large enough can the material behave homogeneously. Moreover, the elastic recovery of the indentation after 
unloading, which is independent of the magnitude of the indentation, has a larger influence at lower loads.

The low hardness value found at 3 and $5 \mathrm{kgf}$ for the cermet sintered for $0 \mathrm{~min}$ was due to the high porosity and the poor neck quality between the binder and ceramic phases as a result of a deficient densification. The high hardness value at $1 \mathrm{~kg}$ was not representative; the detrimental effect of porosity was not observed due to the small size of the indentation mark. The low-porosity cermets sintered for $30 \mathrm{~min}$ and $60 \mathrm{~min}$ showed higher and similar hardness at 3 and $5 \mathrm{kgf}$. Finally, the high hardness value observed at $3 \mathrm{kgf}$ for the cermet sintered for $180 \mathrm{~min}$ was attributed to the presence of the large ceramic agglomerates mentioned above (see figure $2 \mathrm{~d}$ ) that contributed significantly to the hardness.

Furthermore, figure $3 \mathrm{c}$ shows that the hardness tended to decrease with sintering time as a consequence of the increased $\lambda$, i.e., the contribution of the binder phase to the hardness. The failure in this expected trend for some loads in cermets sintered for 0 and 180 min was the direct consequence of their microstructural features, such as the existence of porosity/lack of cohesion and the presence of large ceramic agglomerates, respectively.

The evaluated fracture toughness $\left(\mathrm{K}_{\mathrm{Ic}}\right)$ using the IM method from the indentations at $5 \mathrm{kgf}$ is shown in table 1 and figure $3 \mathrm{~d}$. This method has proved to be applicable for many relatively low-toughness cemented carbides. The low values observed were attributed to the presence of a brittle intermetallic phase (and not a tough metal) acting as a binder. Figure $3 d$ and table 1 show that $K_{I c}$ increased with $\lambda$ (or decreased with $\boldsymbol{C}$ ). The effective operation of the ductile ligament bridging (constrained binder) and the crack deflection (carbide size effect) are prominent toughening mechanisms that are directly related to the microstructural parameters $\boldsymbol{\lambda}$ and $\boldsymbol{C}$. The 
most relevant toughening mechanism is the shielding due to the ductile ligament bridging behind the crack tip. In this case, the enhancement to the toughness is mostly a result of the increased energy in the constrained plastic stretching of the binder ligaments. The toughness increases with the crack extension up to a maximum steadystate level, $\mathrm{K}_{\mathrm{Ic}}$, corresponding to the bridging length where the ligament zone is fully developed (R-Curve behaviour).

The biaxial flexural strength behaviour was analysed in terms of contiguity (figure 3e). The sintering time reduces the porosity, improves the neck quality and makes softer pore contours. The poor quality of the necks and the high porosity for the cermet with no soaking time at the maximum sintering temperature explain their reduced strength. Cermets sintered for 30 and $60 \mathrm{~min}$ showed the expected trend. The lower flaw sizes obtained at 60 min would explain the improvement in biaxial strength. However, the cermet sintered for 180 min had a lower mechanical strength, despite the role played by the toughening mechanisms (higher $\lambda$ ). This is associated with the increased porosity located within the large ceramic agglomerates and is in agreement with the larger flaw size observed in this case.

Figure 4 shows examples of the defects that caused the fractures; the defects were related to the typical heterogeneities inherent to the pressure-less processing used: binder-less carbonitride clusters in figure $4 \mathrm{a}$, pores in figures $4 \mathrm{~b}$ and $4 \mathrm{~d}$, and coarse carbonitrides in figure 4c. A detailed analysis using a larger magnification of the fracture surface was carried out to discern the associated micromechanisms. Dimple ductile rupture in the interdispersed metallic binder and transgranular cleavage in the carbonitride particles were the most relevant fractographic features (highlighted with circles or arrows in figure 5, respectively). As the binder mean free path increased with the sintering time, the microstructure interactions involving large carbonitrides 
exhibited a transgranular character, as observed from the river pattern features. The results showed an acceptable agreement between the estimated and experimentally measured critical flaw sizes. This assertion is sustained through a fracture mechanics analysis combining a fracture toughness evaluation, a biaxial strength measurement and a fractographic examination. 


\section{CONCLUSIONS.}

CSC cermets based on titanium-tantalum carbonitride as the hard phase and intermetallic Ta-Ti-Co as the binder phase were fabricated via pressure-less sintering from powders obtained through a mechanochemical process. The microstructure of these cermets was varied by modifying the soaking time from 0 to $180 \mathrm{~min}$ at the sintering temperature $\left(1500^{\circ} \mathrm{C}\right)$, and a complete mechanical characterisation was carried out. The following conclusions were drawn from this work:

- CSC cermets have a granular microstructure similar to that of conventional WCCo and their mechanical behaviour can be explained as a function of the key two-phase microstructural parameters, $\boldsymbol{\lambda}$ and $\boldsymbol{C}$.

- The mechanical characterisation showed that the hardness tended to decrease with $\lambda$, whereas the indentation toughness and the flexural strength tended to increase.

- The best combination of mechanical properties was found in the cermet sintered for $60 \mathrm{~min}$ because an adequate densification and microstructure were reached. Reducing the sintering time resulted in cermets with higher porosity and deficient cohesion between ceramic and binder phases. Extending the sintering time induced the formation of large ceramic agglomerates, which deteriorate the mechanical properties.

- The low indentation toughness observed for all cermets was due to the presence of a brittle intermetallic phase acting as binder.

- The fractographic examination showed that the presence of binder-less carbonitride clusters, pores and coarse carbonitride grains were the main defects 
that induced fractures and the low flexural strength. A good agreement between the estimated and experimentally measured critical flaw sizes was found.

- Dimple ductile rupture in the binder and transgranular cleavage in the ceramic particles were the main fracture micromechanisms observed.

\section{Acknowledgments}

This work was supported by the Spanish government under grant No. MAT2011-22981, which was financed in part by the European Regional Development Fund of 2007-2013. E. Chicardi and J. M. Córdoba were supported by the CSIC through JAE-Pre and JAE-Doc grants, respectively, which are financed in part by the European Social Fund (ESF). 


\section{REFERENCES}

[1] Czura RJ. Cermets tackle tough jobs. Modern Machine Shop. 1989;62:66-74.

[2] Ettmayer P, Kolaska H, Lengauer W, Dreyer K. Ti(C,N) Cermets - Metallurgy and Properties. International Journal of Refractory Metals and Hard Materials. 1995;13:343.

[3] Kolaska H. Cermets. Cutting materials with a future. Wire. 1990;40:343-6.

[4] Wick C. Cermet cutting tools. Manufacturing Engineering. 1987;99:35-40.

[5] Zhang SY. Titanium carbonitride based-cermets- Processes and properties. Materials Science and Engineering a-Structural Materials Properties Microstructure and Processing. 1993;163:141-8.

[6] Kieffer R, Ettmayer P, Freudhofmeier M. Modern development in powder metallurgy. Ed. H. H. Hausner. Plenum Press. New York 1971.

[7] Mun S, Kang S. Effect of HfC addition on microstructure of Ti(CN)-Ni cermet system. Powder Metallurgy. 1999;42:251-6.

[8] Askarova LK, Shchipachev EV, Ermakov AN, Grigorov IG, Zainulin YG. Effects of vanadium and niobium on the phase composition of titanium carbonitride-base cermets with titaniumnickel binder. Inorganic Materials. 2001;37:157-60.

[9] Kim S, Zuo JM, Kang S. Effect of WC or NbC addition on lattice parameter of surrounding structure in $\mathrm{Ti}(\mathrm{C}(0.7) \mathrm{N}(0.3))$-Ni cermets investigated by TEM/CBED. Journal of the European Ceramic Society. 2010;30:2131-8.

[10] Wu P, Zheng Y, Zhao Y, Yu H. Effect of TaC addition on the microstructure and mechanical properties of Ti(C,N)-based cermets. Materials \& Design. 2010;31:3537-41.

[11] Lindahl P, Gustafson P, Rolander U, Stals L, Andren HO. Microstructure of model cermets with high Mo or W content. International Journal of Refractory Metals and Hard Materials. 1999;17:411-21.

[12] Isobe K, Kitagawa N, Yamazaki I. Titanium-based alloy. United States Patent 5939651. 1999.

[13] Kim JW, Ahn SY, Kang S. Effect of the complete solid-solution phase on the microstructure of Ti(CN)-based cermet. International Journal of Refractory Metals and Hard Materials. 2009;27:224-8.

[14] Liu Y, Jin YZ, Yu HJ, Ye JW. Ultrafine $(T i, M)(C, N)$-based cermets with optimal mechanical properties. International Journal of Refractory Metals and Hard Materials. 2011;29:104-7.

[15] Córdoba JM, Sayagués MJ, Alcalá MD, Gotor FJ. Monophasic TiyNb1-yCxN1-x nanopowders obtained at room temperature by MSR. Journal of Materials Chemistry. 2007;17:650-3.

[16] Chicardi E, Córdoba JM, Sayagués MJ, Gotor FJ. Absence of the core-rim microstructure in TixTa1-xCyN1-y-based cermets developed from a pre-sintered carbonitride master alloy. International Journal of Refractory Metals and Hard Materials. 2012;33:38-43.

[17] Roebuck B, Almond EA. Deformation and fracture processes and the physical metallurgy of WC-Co hardmetals. Int Mater Rev. 1988;33:90-110.

[18] Mingard KP, Roebuck B, Bennett EG, Gee MG, Nordenstrom H, Sweetman G, et al. Comparison of EBSD and conventional methods of grain size measurement of hardmetals. International Journal of Refractory Metals and Hard Materials. 2009;27:213-23.

[19] Lee HC, Gurland J. Hardness and deformation of cemented tungsten carbide. Materials Science and Engineering. 1978;33:125-33.

[20] ASTM C373-88. Standard Test Method for Water Absortion Bulk density. Apparent Porosity and Apparent Specific Gravity of Fired Whiteware Products. 1999.

[21] Nondestructive evaluation and quality control. Metals Handbook. Ninth Edition. 1989;235. [22] Shetty DK, Wright IG, Mincer PN, Clauer AH. Indentation Fracture of WC-Co cermets. Journal of Materials Science. 1985;20:1873-82.

[23] Niihara K. A fracture-mechanics analysis of indentation-induced Palmqvist crack in ceramics. Journal of Materials Science Letters. 1983;2:221-3. 
[24] Börger A, Supancic P, Danzer R. The ball on three balls test for strength testing of brittle discs: Stress distribution in the disc. Journal of the European Ceramic Society. 2002;22:142536.

[25] Börger A, Supancic P, Danzer R. The ball on three balls test for strength testing of brittle discs: Part II: Analysis of possible errors in the strength determination. Journal of the European Ceramic Society. 2004;24:2917-28.

[26] Danzer R, Harrer W, Supancic P, Lube T, Wang Z, Börger A. The ball on three balls testStrength and failure analysis of different materials. Journal of the European Ceramic Society. 2007;27:1481-5.

[27] Fett T, Rizzi G, Ernst E, Müller R, Oberacker R. A 3-balls-on-3-balls strength test for ceramic disks. Journal of the European Ceramic Society. 2007;27:1-12.

[28] Shetty DK, Rosenfield AR, McGuire P, Bansal GK, Duckworth WH. Biaxial flexure tests for ceramics. American Ceramic Society Bulletin. 1980;59:1193-7.

[29] Chicardi E, Córdoba JM, Sayagués MJ, Gotor FJ. Inverse core-rim microstructure in $(\mathrm{Ti}, \mathrm{Ta})(\mathrm{C}, \mathrm{N})$-based cermets developed by a mechanically induced self-sustaining reaction. International Journal of Refractory Metals and Hard Materials. 2012;31:39-46.

[30] Thorvaldsen A. The intercept method 2. Determination of spatial grain size. Acta Mater. 1997;45:595-600.

[31] Matikas TE, Karpur P, Crane RL. Ultrasonic measurement of elastic moduli of porous powder metallurgical samples. Bellingham: Spie - Int Soc Optical Engineering; 1996.

[32] Ryshkewitch E. Compression strength of porous sintered alumina and zirconia. Journal of the American Ceramic Society. 1953;36:65-6.

[33] Russias J, Cardinal S, Aguni Y, Fantozzi G, Bienvenu K, Fontaine J. Influence of titanium nitride addition on the microstructure and mechanical properties of TiC-based cermets.

International Journal of Refractory Metals and Hard Materials. 2005;23:358-62.

[34] Shackelford JF; Alexander W. Mechanical Properties of Materials. CRC Materials Science and Engineering Handbook, Third Edition. CRC Press; 2000.

[35] Fleck NA, Hutchinson JW. Strain Gradient Plasticity. 1997;295-361.

[36] Gao H, Huang Y, Nix WD, Hutchinson JW. Mechanism-based strain gradient plasticity - I. Theory. Journal of the Mechanics and Physics of Solids. 1999;47:1239-63.

[37] Nix WD, Gao H. Indentation size effects in crystalline materials: A law for strain gradient plasticity. Journal of the Mechanics and Physics of Solids. 1998;46:411-25. 


\section{FIGURE CAPTIONS.}

Figure 1. X-ray powder diffraction diagrams of cermets sintered at $1550{ }^{\circ} \mathrm{C}$ for increasing times: (a) $0 \mathrm{~min}$, (b) $30 \mathrm{~min}$, (c) $60 \mathrm{~min}$, and (d) $180 \mathrm{~min}$.

$(\bullet) \mathrm{Ti}_{0.85} \mathrm{Ta}_{0.15} \mathrm{C}_{0.67} \mathrm{~N}_{0.33}, F m 3 m ;(\circ) \mathrm{Ti}_{\mathrm{x}} \mathrm{Ta}_{1-\mathrm{x}} \mathrm{Co}_{2}, P 6_{3} / m m c ;(\diamond) \mathrm{Ti}_{\mathrm{x}} \mathrm{Ta}_{1-\mathrm{x}} \mathrm{Co}, R-3 m$.

Figure 2. SEM micrographs and some microstructural parameters of cermets sintered at $1550{ }^{\circ} \mathrm{C}$ with increasing sintering time: (a) $0 \mathrm{~min}$, (b) $30 \mathrm{~min}$, (c) $60 \mathrm{~min}$, and (d) 180 $\min$.

Figure 3. Physical and mechanical properties of sintered cermets: (a) porosity and Young's modulus as a function of sintering time, (b) estimation of Young's modulus for a fully dense cermet, (c) Vickers hardness as a function of sintering time and applied load, (d) Vickers hardness and indentation toughness, $\mathrm{K}_{\mathrm{IC}}$, as a function of binder mean free path, and (e) biaxial flexural strength as a function of ceramic contiguity.

Figure 4. Low-magnification SEM micrographs of the fractured surfaces of the sintered cermets generated by the biaxial flexural strength tests (ball on three balls), showing the defects that caused the fractures: (a) $0 \mathrm{~min}$, (b) $30 \mathrm{~min}$, (c) $60 \mathrm{~min}$, and (d) $180 \mathrm{~min}$.

Figure 5. High-magnification SEM micrographs of the fractured surfaces of the sintered cermets, showing the different existing flaws (ductile dimples, marked with circles; transgranular cleavage, marked with arrows) susceptible to cause the chaotic fracture: (a) 0 min, (b) $30 \mathrm{~min}$, (c) $60 \mathrm{~min}$, and (d) $180 \mathrm{~min}$. 
Table I. Microstructural and mechanical parameters of sintered cermets.

\begin{tabular}{|c|c|c|c|c|c|c|c|c|}
\hline \multirow{2}{*}{$\begin{array}{c}\text { Sintering } \\
\text { time } \\
(\mathrm{min})\end{array}$} & \multirow{2}{*}{$\mathbf{C}$} & \multirow{2}{*}{$\begin{array}{c}\lambda \\
(\mu \mathrm{m})\end{array}$} & \multirow{2}{*}{$\begin{array}{c}\mathbf{E}_{\mathbf{d}} \\
(\mathbf{G P a})\end{array}$} & \multirow{2}{*}{$\begin{array}{l}\text { HV5 } \\
\text { (GPa) }\end{array}$} & \multirow{2}{*}{$\begin{array}{c}\mathbf{K}_{\mathrm{Ic}}^{(\mathrm{I})} \\
\left(\mathbf{M P a} \mathbf{m}^{\mathbf{1} \mathbf{2}}\right)\end{array}$} & \multirow{2}{*}{$\begin{array}{c}\sigma_{\mathrm{BFS}} \\
(\mathrm{MPa})\end{array}$} & \multicolumn{2}{|c|}{ Critical flaw size, 2 a $(\mu \mathrm{m})$} \\
\hline & & & & & & & $\underset{\text { (II) }}{\text { Estimated }}$ & $\underset{\text { (III) }}{\text { Experimental }}$ \\
\hline 0 & 0.59 & 0.90 & 228 & 9.6 & 3.6 & 281 & 257 & 229 \\
\hline 30 & 0.51 & 1.04 & 446 & 11.0 & 4.2 & 319 & 272 & 252 \\
\hline 60 & 0.47 & 1.15 & 644 & 10.4 & 4.2 & 354 & 221 & 236 \\
\hline 180 & 0.41 & 1.44 & 321 & 10.4 & 5.2 & 307 & 451 & 446 \\
\hline
\end{tabular}



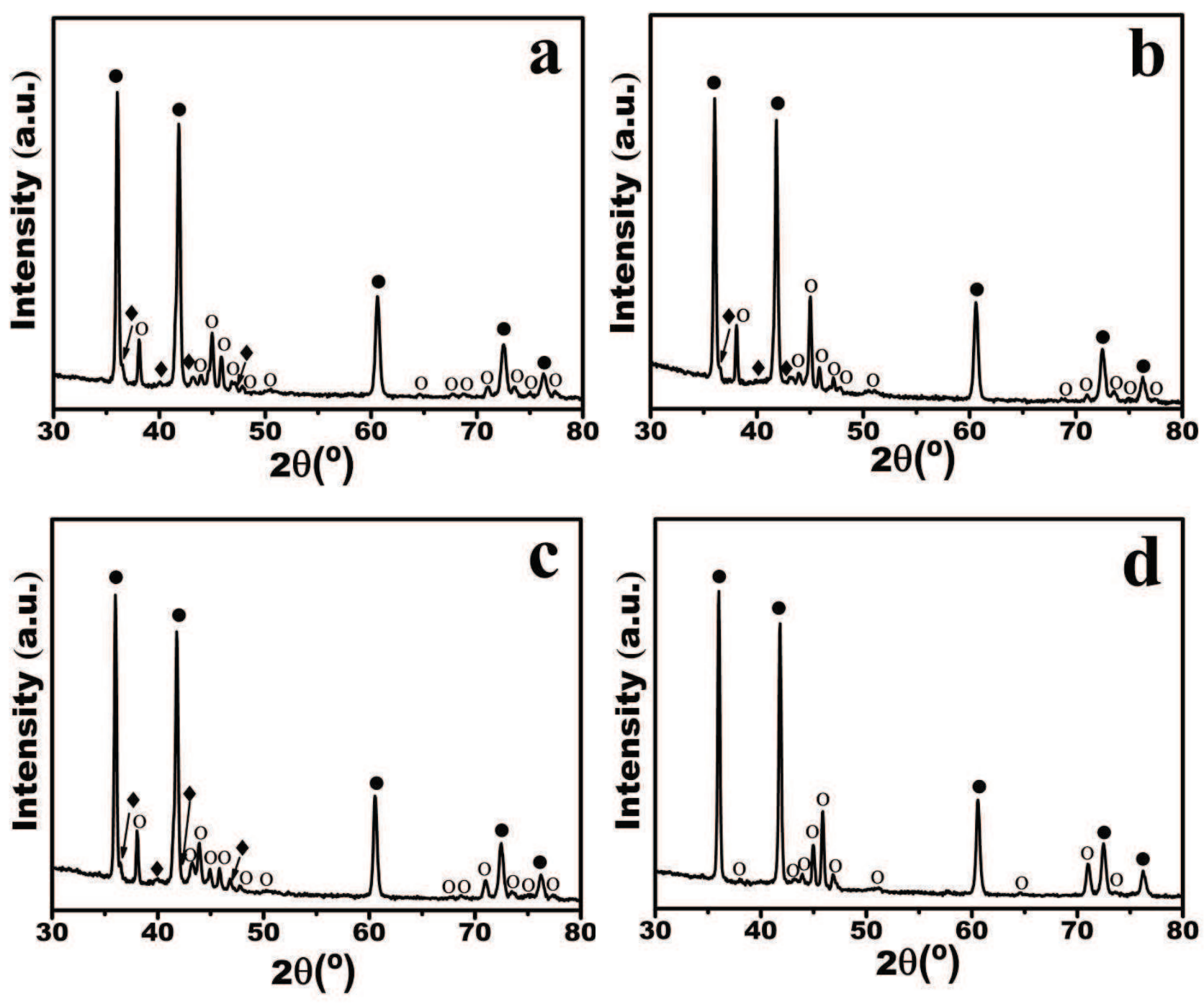

Figure 1 

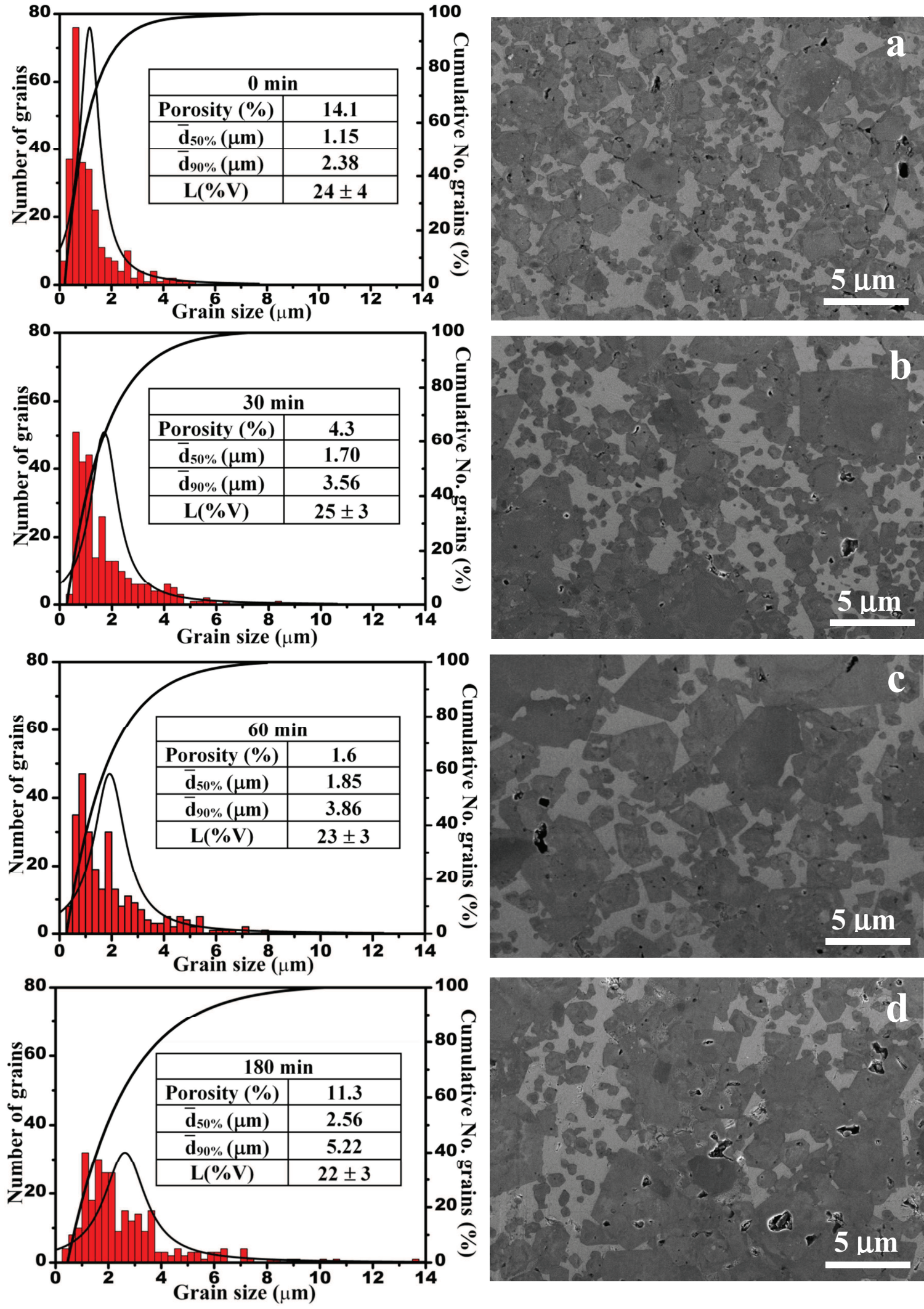

Figura 2 

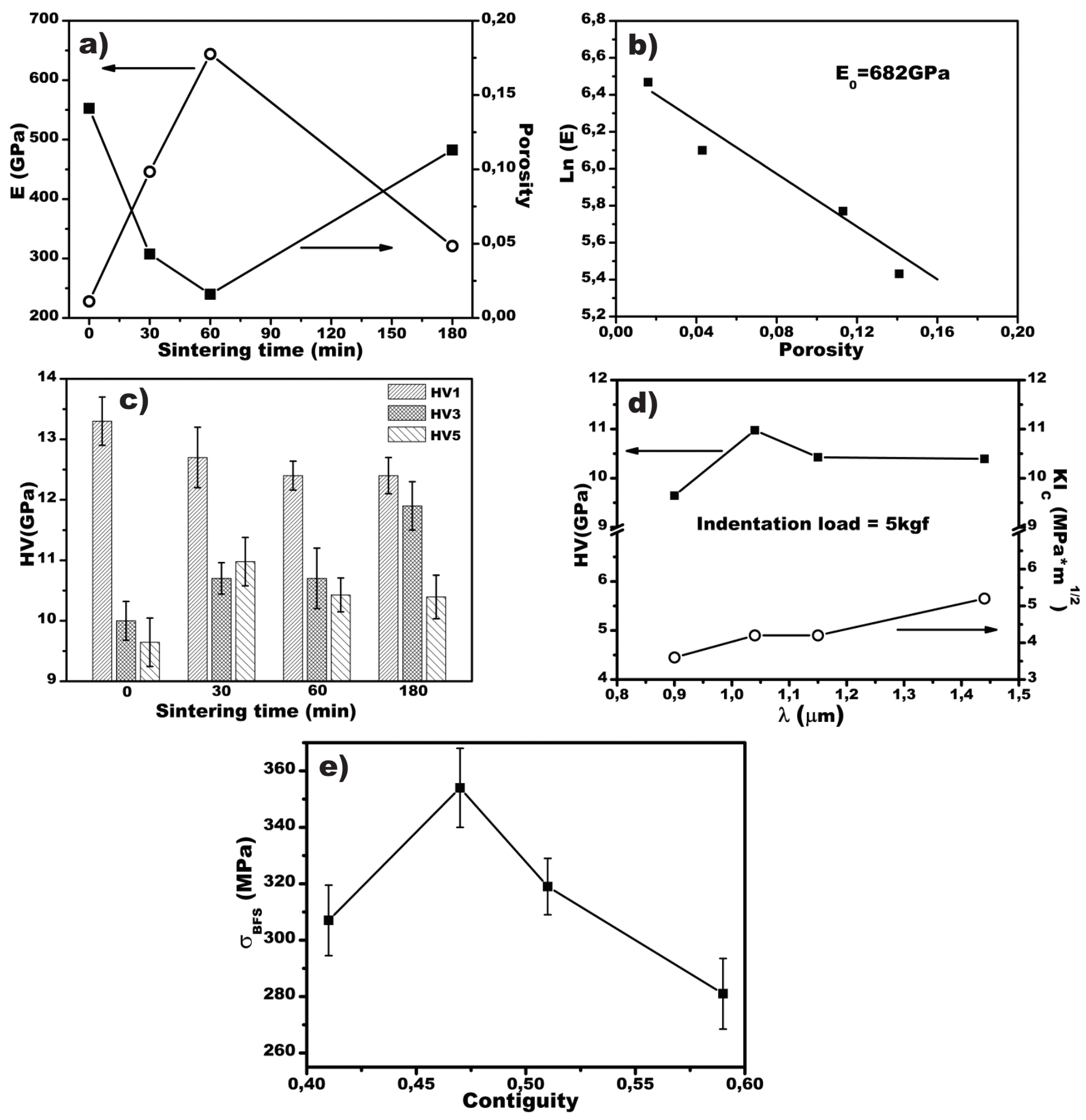

Figura 3 


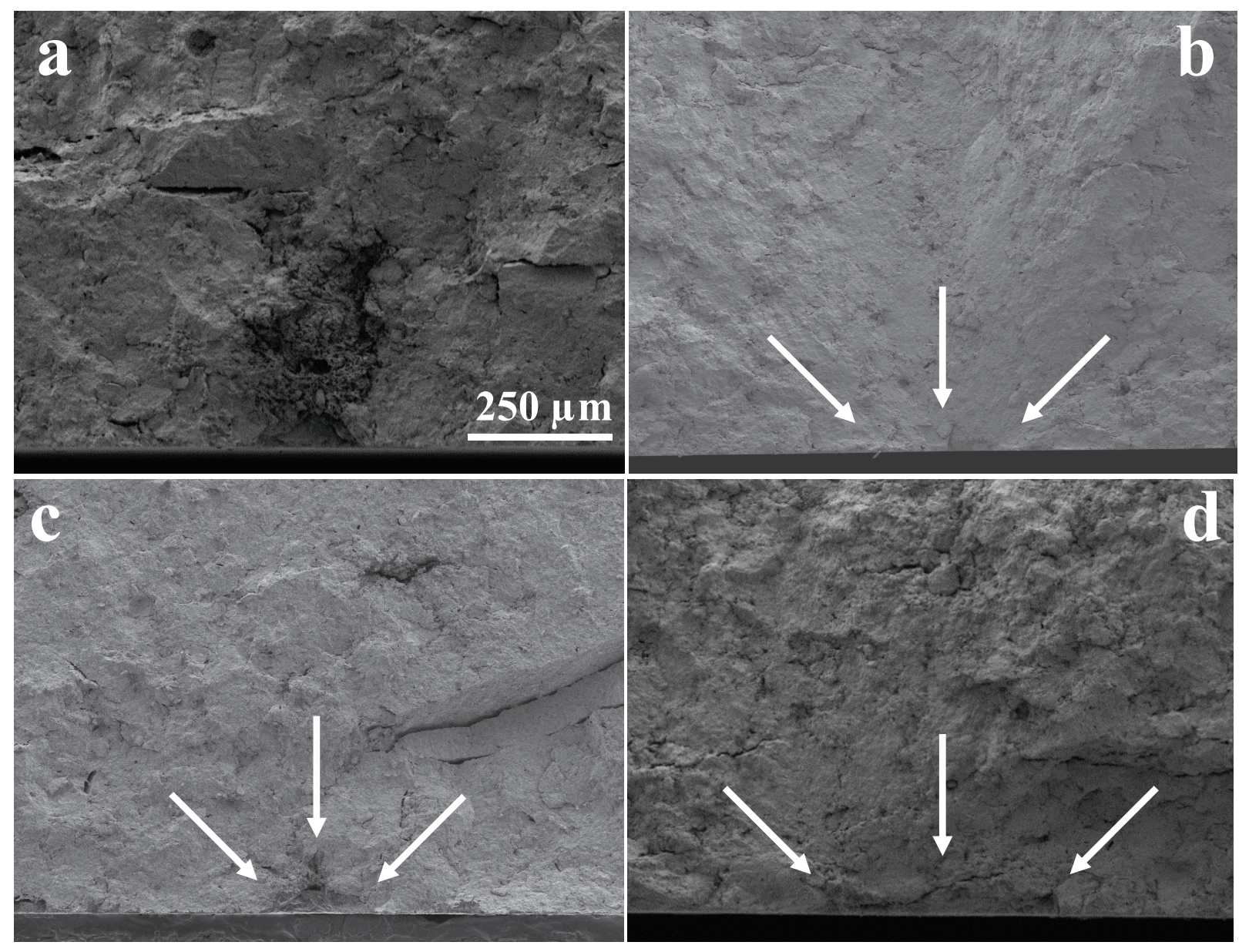

Figure 4 
Figure 5
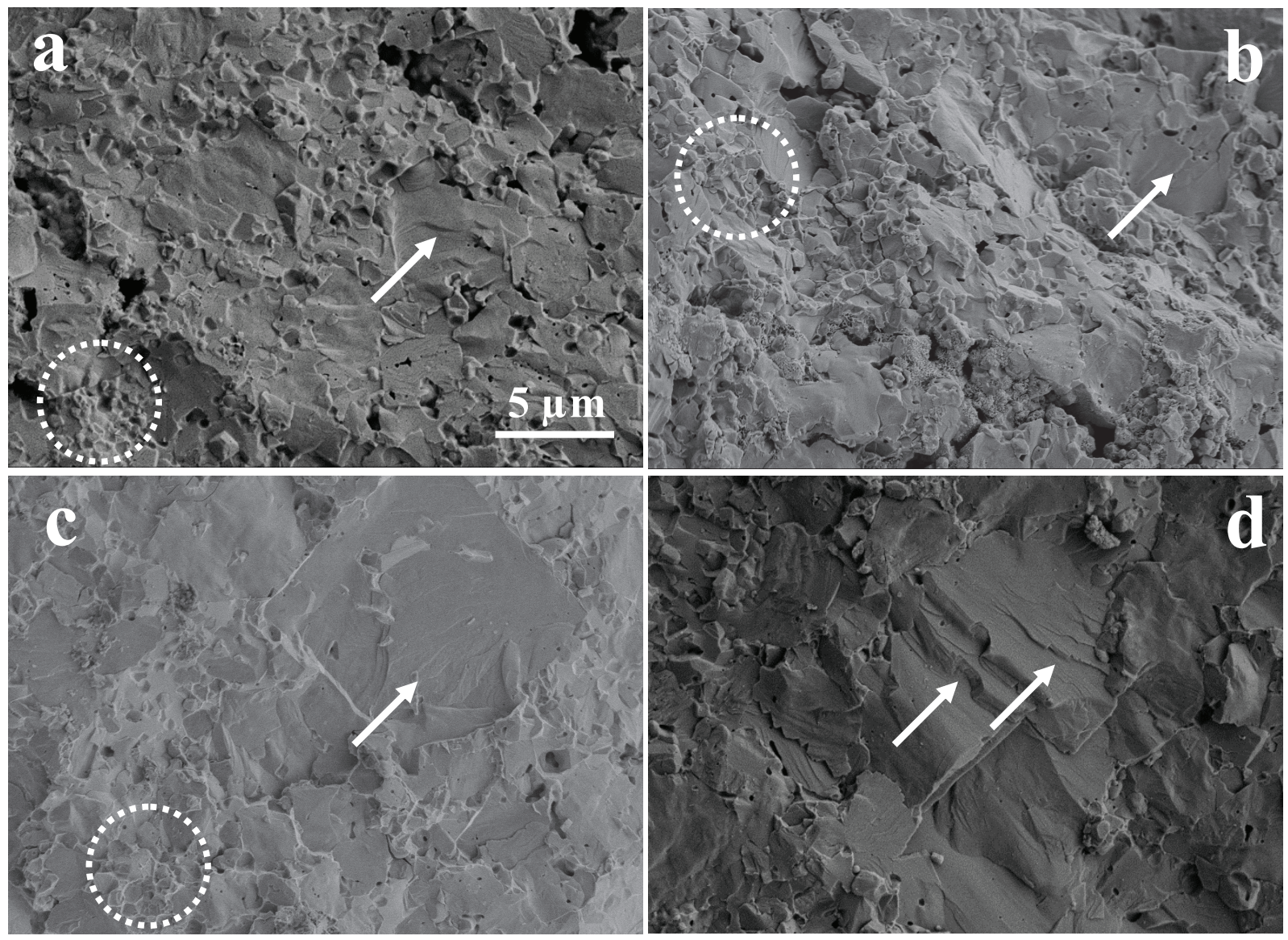

Figure 5 